\title{
PENERAPAN ANALISIS REGRESI DATA PANEL PADA INDEKS PEMBANGUNAN MANUSIA DI PROVINSI PAPUA BARAT
}

\author{
Application Of Panel Data Regression Analysis to The Human Development Index in \\ The Province Of West Papua
}

\author{
Desti Setya Ningsih $^{1}$, Esther Ria Matulessy ${ }^{2}$, Dariani Matualage ${ }^{3}$ \\ ${ }^{123}$ Jurusan Matematika, Fakultas Matematika dan Ilmu Pengetahuan Alam, UNIPA, Manokwari \\ Email: destisetya2412@gmail.com
}

\begin{abstract}
Panel Data Regression Analysis is a combination of time series data and cross section data. The purpose of this study is to determine the best model for panel data regression analysis on HDI in West Papua Province and to determine the HDI model in West Papua Province. The data used in this study are West Papua data in the 2019 Publication Figures and 2019 Publication Human Development Index data. In the process of determining the best model, estimating model parameters with 3 approaches namely CEM, FEM and REM, then testing model selection, classical assumption test, model equation checking and finally model interpretation. The results of this study indicate that the best regression model is FEM with individual effects and time effects with a good model of $91 \%$ which means that HDI in West Papua Province is explained by GRDP, RLS, JPM and UHH. The equation model is as follows:

$$
\hat{Y}_{1 t}=\hat{\alpha}_{0 i}+0,03 X_{1 i t}+6,31 X_{2 i t}+0,05 X_{3 i t}+0,23 X_{4 i t}
$$

Based on the equations that have been obtained, the variables that have a significant effect on HDI in West Papua Province are RLS and UHH.
\end{abstract}

Keywords: Panel Data Regression, CEM, FEM, REM

\begin{abstract}
ABSTRAK
Analisis Regresi Data Panel merupakan gabungan antara data time series dan data cross section. Tujuan dari penelitian ini adalah menentukan model terbaik analisis regresi data panel pada IPM di Provinsi Papua Barat dan menentukan model IPM di Provinsi Papua Barat. Data yang digunakan dalam penelitian ini merupakan berupa data Papua Barat Dalam Angka Publikasi Tahun 2019 dan data Indeks Pembangunan Manusia Publikasi Tahun 2019. Dalam proses penentuan model terbaik, dilakukan pendugaan parameter model dengan 3 pendekatan yakni CEM, FEM dan REM, kemudian uji pemilihan model, uji asumsi klasik, pemeriksaan persamaan model dan terakhir interpretasi model. Hasil penelitian ini menunjukkan bahwa model regresi terbaik adalah FEM dengan efek individu dan efek waktu dengan kebaikan model sebesar 91\% yang dapat diartikan bahwa IPM di Provinsi Papua Barat dijelaskan oleh PDRB, RLS, JPM dan UHH. Model persamaannya sebagai berikut:

$$
\hat{Y}_{1 t}=\hat{\alpha}_{0 i}+0,03 X_{1 i t}+6,31 X_{2 i t}+0,05 X_{3 i t}+0,23 X_{4 i t}
$$

Berdasarkan persamaan yang telah diperoleh, variabel yang berpengaruh signifikan terhadap IPM di Provinsi Papua Barat adalah RLS dan UHH.
\end{abstract}

Kata Kunci: Regresi Data Panel, CEM, FEM, REM 


\section{PENDAHULUAN}

Analisis regresi merupakan metode statistika yang digunakan untuk menganalisis hubungan antar variabel yang dibentuk dalam suatu persamaan regresi. Variabel yang dimaksud adalah variabel bebas $(X)$ atau independent dengan variabel terikat $(Y)$ atau dependent. Bila melibatkan satu variabel bebas, maka analisis yang digunakan adalah analisis regresi sederhana. Bila melibatkan lebih dari satu variabel bebas, maka analisis yang digunakan adalah analisis regresi berganda (Walpole, 1992). Analisis regresi juga ada yang melibatkan unsur waktu disebut analisis regresi runtun waktu atau time series. Analisis regresi juga digunakan untuk melihat variabel bebas mana saja yang berhubungan dengan variabel terikat untuk mengetahui bentukbentuk hubungan tersebut salah satunya adalah analisis regresi data silang atau cross section (Makridakis et al., 1999).

Menurut Baltagi (2005) gabungan antara data time series dan cross section disebut data panel. Data time series meliputi satu variabel bebas tetapi terdapat beberapa periode (bisa harian, bulanan atau tahunan). Sedangkan data cross section terdiri dari beberapa atau banyak variabel bebas dengan jenis data dalam satu periode waktu tertentu. Nachrowi dan Usman (2006) mengemukakan karena data panel merupakan gabungan dari cross sectiondan data time series, maka tentunya akan mempunyai observasi lebih banyak dibanding data time series atau data cross section saja. Akibatnya, ketika digabungkan menjadi data panel dalam analisis regresi, maka hasilnya cenderung akan lebih baik dibanding analisis regresi yang hanya menggunakan data time series atau cross section saja.

Penyelesaian analisis regresi dapat dilakukan dengan menggunakan Metode Kuadrat Terkecil (MKT). Metode ini akan memberikan hasil yang bersifat Best Linear Unbiased Estimation (BLUE), jika semua asumsi terpenuhi diantaranya adalah tidak terjadi autokorelasi. Terjadinya autokorelasi dapat ditandai dengan adanya korelasi antara residual pada satu pengamatan dengan pengamatan lain pada model regresi. Penanganan autokorelasi dapat menggunakan transformasi, yaitu dengan mengurangi nilai variabel (bebas dan terikat) pada waktu ke-t, dengan waktu ke-(t-1) (Gujarati 2004). Menurut Wooldridge (2002) pada data panel autokorelasi sudah dapat diatasi karena menggabungkan data time series dan data cross section yang akan memberikan informasi keragaman variabel bebas yang diamati pada jangka waktu tertentu.

Menurut Hsiao (2003) terdapat beberapa keuntungan dalam menggunakan analisis regresi data panel. Pertama, data panel mampu memperhitungkan heterogenitas individu secara eksplisit 
dengan mengizinkan variabel spesifik individu. Kedua, data panel memiliki kemampuan mengontrol heterogenitas membangun model perilaku lebih kompleks. Ketiga, tingginya jumlah observasi memiliki implikasi pada data yang lebih informatif, lebih variatif, dan kolinearitas antar variabel (multikol) semakin berkurang dan menghasilkan nilai derajat bebas yang tinggi sehingga dapat diperolah hasil estimasi yang lebih efisien. keempat, data panel juga dapat meminimalkan bias yang mungkin ditimbulkan oleh agregasi data individu.

Analisis regresi data panel telah banyak diaplikasikan dalam beberapa penelitian, seperti yang dilakukan oleh Lestari dan Setyawan (2017) tentang Analisis Regresi Data Panel Untuk Mengetahui Faktor Yang Mempengaruhi Belanja Di Provinsi Jawa Tengah. Hasil yang diperoleh adalah dari ke enam variabel yang diduga berpengaruh terhadap belanja daerah ternyata ada lima variabel yang berpengaruh dan model yang terbaik yaitu Random Effect Model (REM) dengan efek individu dan waktu. Penelitian juga pernah dilakukan oleh Riski et al. (2015) tentang Pemodelan Indeks Pembangunan Manusia di Provinsi Jawa Tengah Tahun 2008-2013 dengan Menggunakan Regresi Data Panel. Hasil yang diperoleh yaitu model yang sesuai dengan Pemodelan Indeks Pembangunan Manusia di Provinsi Jawa sehingga dapat digunakan untuk menguji dan

Tengah Tahun 2008-2013 adalah Fixed Effects Model (FEM).

Menurut publikasi Badan Pusat Statistika atau BPS (2019) tentang status pembangunan manusia di Provinsi Papua Barat yang terus mengalami kemajuan. Pada Tahun 2018 IPM Papua Barat mencapai $63,74 \%$ dan secara umum masih dapat dikatakan dalam kategori sedang. Namun, jika dibandingkan dengan semua provinsi di Indonesia, Papua Barat berada pada peringkat terbawah kedua, diatas Provinsi Papua. Data IPM di Provinsi Papua Barat tergolong data panel karena memiliki 2 unsur, yakni unsur data time series dan data cross section. Unsur data time seriesdapat diketahui dari adanya capaian IPM yang dipublikasi oleh BPS secara berkala dalam bentuk publikasi tahunan. Sedangkan unsur cross section dapat diketahui dari adanya faktor-faktor yang dapat mempengaruhi IPM yang dipublikasikan secara berkala oleh BPS.

IPM dapat dilihat berdasarkan tiga dimensi yaitu:Usia Panjang dan Sehat, Pengetahuan dan Kehidupan Layak. Indikator Usia Harapan Hidup (UHH) mengukur dimensi Usia Panjang dan Sehat dan indikator Rata-rata Lama Sekolah (RLS) mengukur dimensi Pengetahuan (BPS, 2019). Menurut Irjaya (2017) terdapat faktor-faktor lain yang dapat mempengaruhi 
IPM pada dimensi Kehidupan Layak, yaitu Produk Domestik Regional Bruto (PDRB) dan jumlah penduduk miskin. PDRB merupakan jumlah nilai tambah bruto (gross value added) yang timbul dari seluruh sektor perekonomian disuatu wilayah. Jumlah penduduk miskin juga sangat mempengaruhi tinggi rendahnya IPM. Berdasarkan uraian yang telah dijabarkan, maka penulis bermaksud untuk melakukan penelitian mengenai "Penerapan Analisis Regresi Data Panel Pada Indeks Pembangunan Manusia di Provinsi Papua Barat". Adapun tujuan dari penelitian ini adalah menentukan model terbaik analisis regresi data panel pada Indeks Pembangunan Manusia di Provinsi Papua Barat dan menentukan model Indeks Pembangunan
Manusia di Provinsi Papua Barat.

\section{METODE PENELITIAN}

Pada penelitian ini data yang digunakan merupakan data sekunder yang diperoleh dari Badan Pusat Statistika (BPS) Provinsi Papua Barat, berupa data Papua Barat Dalam Angka Tahun 2018, Papua Barat Dalam Angka Tahun 2019 dan Indeks Pembangunan Manusia Tahun 2019. Variabel yang digunakan terdiri dari IPM sebagai variabel terikat sedangkan PDRB, RLS, JPM dan UHH sebagai variabel bebas. Data yang diperoleh akan dioleh menggunakan Microsoft Excel secara manual dan menggunakan software Eviews 9. Adapun prosedur dalam panelitian ini akan ditampilkan pada diagram alir Gambar 1.

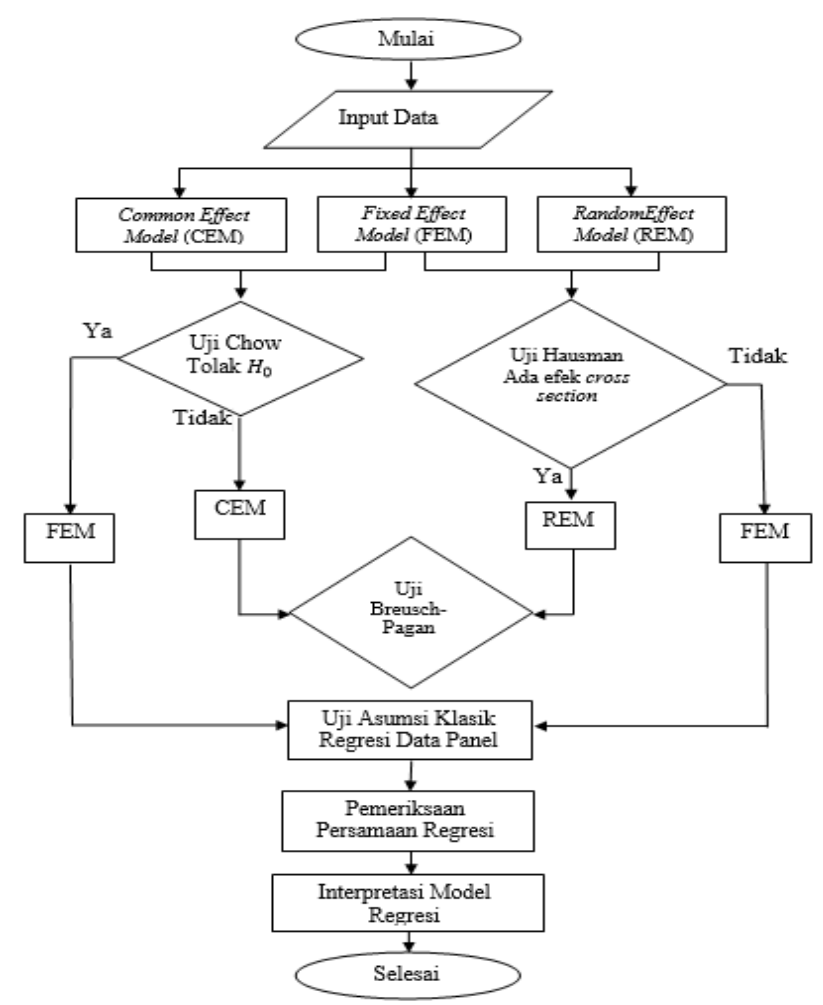

Gambar 1. Prosedur Penelitian 


\section{HASIL DAN PEMBAHASAN}

Pendugaan parameter model regresi data panel dapat memberikan gambaran penuh dari variabel bebas dengan variabel terikat yakni IPM Kabupaten/Kota di Papua Barat. Estimasi parameter model regresi data panel dilakukan melalui tiga pendekatan yakni common effect model (CEM), Fixed Effect Model (FEM) dan Random Effect Model (REM). Hasil estimasi CEM akan disajikan pada Tabel 1 sebagai berikut:

Tabel 1 Hasil estimasi CEM

\begin{tabular}{ccc}
\hline \multirow{2}{*}{ Variabel } & \multicolumn{2}{c}{ Common effect model } \\
\cline { 2 - 3 } & koefisien & nilai p-value \\
\hline Intersep & 22,58 & 0,00 \\
PDRB & 0,04 & 0,69 \\
RLS & 2,91 & 0,00 \\
JPM & 0,18 & 0,00 \\
UHH & 0,23 & 0,00 \\
\hline R $^{2}$ & \multicolumn{3}{c}{0,97} \\
F $_{\text {hitung }}$ & 395,45 \\
DW $_{\text {hitung }}$ & 0,18 \\
\hline
\end{tabular}

Model yang diperoleh pada pendekatan CEM menghasilkan nilai $\mathrm{R}^{2}$ sebesar 0,97. Dapat diartikan bahwa semua variabel bebas dalam model dapat menjelaskan variabel terikat IPM kabupaten/kota sebesar 97\%. Kemudian dilanjutkan dengan estimasi menggunakan pendekatan FEM yang dapat dilihat pada Tabel 2.
Tabel 2 Hasil Estimasi FEM

\begin{tabular}{|c|c|c|}
\hline Variable & Coefficient & Prob. \\
\hline Intersep & 0,16 & 0,98 \\
\hline PDRB & 0,03 & 0,38 \\
\hline RLS & 6,31 & 0,00 \\
\hline Kemiskinan & 0,05 & 0,51 \\
\hline $\mathrm{UHH}$ & 0,23 & 0,03 \\
\hline \multicolumn{3}{|l|}{ Fixed Effects (Cross) } \\
\hline Fakfak & $-3,12$ & \\
\hline Kaimana & $-2,50$ & \\
\hline Teluk Wondama & 1,60 & \\
\hline Teluk Bintuni & $-0,68$ & \\
\hline Manokwari & 3,03 & \\
\hline Sorong Selatan & $-0,05$ & \\
\hline Sorong & $-1,49$ & \\
\hline Raja Ampat & $-0,72$ & \\
\hline Tambrauw & 6,65 & \\
\hline Maybrat & 0,89 & \\
\hline Manokwari Selatan & 1,54 & \\
\hline Pegunungan Arfak & 7,29 & \\
\hline Kota Sorong & $-10,40$ & \\
\hline $\mathrm{R}^{2}$ & 0.91 & \\
\hline $\mathrm{F}_{\text {hitung }}$ & 122,77 & \\
\hline DW & 1,73 & \\
\hline
\end{tabular}

Berdasarkan Tabel 2 diperoleh hasil nilai $\mathrm{R}^{2}$ sebesar 0,91 dengan efek individu dan efek waktu. Dapat diartikan bahwa keragaman variabel bebas dapat dijelaskan oleh model sebesar 91\% yang dipengaruhi oleh efek individu dan waktu. Pada pendekatan FEM terdapat intersep setiap kabupaten/kota berbeda-beda. Terakhir yaitu dilakukan estimasi parameter pendekatan REM yang akan disajikan pada Tabel 3 . 
Tabel 3 Hasil estimasi REM

\begin{tabular}{|c|c|c|}
\hline Variable & Coefficient & Prob. \\
\hline Intersep & 7,33 & 0,11 \\
\hline PDRB & 0,06 & 0,07 \\
\hline RLS & 4,44 & 0,00 \\
\hline Kemiskinan & $-0,00$ & 0,89 \\
\hline $\mathrm{UHH}$ & 0,34 & 0,00 \\
\hline \multicolumn{3}{|l|}{ Fixed Effects (Cross) } \\
\hline Fakfak & $-1,51$ & \\
\hline Kaimana & $-1,68$ & \\
\hline Teluk Wondama & 0,67 & \\
\hline Teluk Bintuni & 0,71 & \\
\hline Manokwari & 4,82 & \\
\hline Sorong Selatan & $-1,17$ & \\
\hline Sorong & $-0,40$ & \\
\hline Raja Ampat & $-0,52$ & \\
\hline Tambrauw & 1,86 & \\
\hline Maybrat & $-1,02$ & \\
\hline Manokwari Selatan & $-1,01$ & \\
\hline Pegunungan Arfak & 2,28 & \\
\hline Kota Sorong & $-3,04$ & \\
\hline $\mathrm{R}^{2}$ & 0.87 & \\
\hline $\mathrm{F}_{\text {hitung }}$ & 88,56 & \\
\hline DW $_{\text {hitung }}$ & 0,86 & \\
\hline
\end{tabular}

Pendugaan parameter menggunakan pendekatan REM diperoleh nilai $\mathrm{R}^{2}$ sebesar 0,87. Dapat diartikan bahwa variabel bebas dalam model dapat menjelaskan variabel terikat IPM kabupaten/kota sebesar $87 \%$. Pada pendekatan REM juga dapat terlihat intersep setiap kabupaten/kota berbeda-beda. Kemudian dilakukan pemilihan model terbaik dengan menggunakan beberapa pengujian yaitu sebagai berikut:

1. Uji Chow

Uji chow dilakukan untuk mengetahui model terbaik antara FEM dan CEM, diperoleh hasil yang ditampilkan pada Tabel 4.
Tabel 4 Hasil Uji Chow

\begin{tabular}{|c|c|c|}
\hline Effect Test & Statistic & $\begin{array}{c}p- \\
\text { value }\end{array}$ \\
\hline Cross-section F & 66,44 & 0,00 \\
\hline Cross-section Chi-square & 164,78 & 0,00 \\
\hline
\end{tabular}

diperoleh $p$-value $<\alpha$. Maka dapat disimpulkan $H_{0}$ ditolak, sehingga model yang terbaik adalah FEM.

2. Uji Hausman

Uji Hausman untuk memilih model terbaik antara REM dan FEM yang akan ditampilkan pada Tabel 5.

Tabel 5 Hasil Uji Hausman

\begin{tabular}{lcc}
\hline Test Summary & Chi-Sq. Statistic & $p$-value \\
\hline Cross-section & 43,46 & 0,00 \\
random & & \\
\hline
\end{tabular}

Dengan menggunakan uji statistik pada Uji Hausman dimana $W>x_{(\alpha, k)}^{2}$ atau nilai $p$-value kurang pada taraf signifikan sebesar 5\%, diperolehp-value $<\alpha$. Maka dapat disimpulkan $H_{0}$ ditolak yang berarti bahwa model yang terbaik antar adalah FEM.

3. Uji Breusch-Pagan

Uji Breusch-Pagan digunakan untuk mengetahui apakah REM lebih baik dibandingkan CEM. Berdasarkan hasil Uji Chow dan hasil Uji Hausman model yang terbaik adalah FEM, sehingga Uji BreuschPagan tidak diperlu dilakukan.

Berdasarkan hasil pendugaan model yang terbaik adalah FEM, sehingga 
diperoleh model IPM di Provinsi Papua Barat sebagai berikut:

$$
\begin{gathered}
\hat{Y}_{1 t}=\hat{\alpha}_{0 i}+0,03 X_{1 i t}+6,31 X_{2 i t}+0,05 X_{3 i t} \\
+0,23 X_{4 i t}
\end{gathered}
$$

Dengan,

$\widehat{Y}_{1 t} \quad$ : Pendugaan Indeks Pembangunan

Manusia daerah ke $-i$ dan tahun ke- $t$

$X_{1 i t} \quad$ : Product Domestic Regional

Brutodaerah ke $-i$ dan tahun $\mathrm{ke}-t$

$X_{2 i t}$ : Rata-rata Lama Sekolah daerah ke- $i$

dan tahun ke- $t$

$X_{3 i t}$ : Junlah Penduduk Miskin daerah

$\mathrm{ke}-i$ dan tahun $\mathrm{ke}-t$

$X_{4 i t} \quad$ : Usia Harapan Hidup daerah $\mathrm{ke}-i$

dan tahun ke- $t$

Berdasarkan model di atas diketahui bahwa untuk menaikkan IPM dapat dilakukan dengan cara menaikkan semua variabel bebas yaitu $X_{1}, X_{2}, X_{3}$ dan $X_{4}$. Nilai $\hat{\alpha}_{0 i}$ merupakan intersep untuk masingmasing kabupaten/kota dimana nilainya berbeda-beda seperti disajikan pada Tabel 6 Tabel 6 Estimasi Intersep Kabupaten/Kota

\begin{tabular}{ccr}
\hline $\boldsymbol{i}$ & Kabupaten/Kota & $\widehat{\boldsymbol{\alpha}}_{\mathbf{0} \boldsymbol{i}}$ \\
\hline 1 & Fakfak & $-3,12$ \\
2 & Kaimana & $-2,50$ \\
3 & Teluk Wondama & 1,60 \\
4 & Teluk Bintuni & $-0,68$ \\
5 & Manokwari & 3,03 \\
6 & Sorong Selatan & $-0,05$ \\
7 & Sorong & $-1,49$ \\
8 & Raja Ampat & $-0,72$ \\
9 & Tambrauw & 6,65 \\
10 & Maybrat & 0,89 \\
11 & Manokwari Selatan & 1,54 \\
\hline
\end{tabular}

\begin{tabular}{lcr}
\hline 12 & Pagunungan Arfak & 7,29 \\
13 & Kota Sorong & $-10,40$ \\
\hline
\end{tabular}

Berdasarkan Tabel 6 dapat diperoleh intersep tiap kabupaten/kota yang ada di Provinsi Papua Barat. Persamaan regresi untuk masing-masing Kabupaten/Kota di Provinsi Papua Barat yaitu,

$$
\begin{gathered}
\hat{Y}_{1 t}=-3,12+0,03 X_{1 i t}+6,31 X_{2 i t} \\
+0,05 X_{3 i t}+0,23 X_{4 i t} \\
\hat{Y}_{2 t}=-2,50+0,03 X_{1 i t}+6,31 X_{2 i t} \\
+0,05 X_{3 i t}+0,23 X_{4 i t} \\
\hat{Y}_{3 t}=1.60+0,03 X_{1 i t}+6,31 X_{2 i t} \\
+0,05 X_{3 i t}+0,23 X_{4 i t} \\
\hat{Y}_{4 t}=-0.68+0,03 X_{1 i t}+6,31 X_{2 i t} \\
+0,05 X_{3 i t}+0,23 X_{4 i t} \\
\hat{Y}_{5 t}=3.03+0,03 X_{1 i t}+6,31 X_{2 i t} \\
+0,05 X_{3 i t}+0,23 X_{4 i t} \\
\hat{Y}_{6 t}=-0.05+0,03 X_{1 i t}+6,31 X_{2 i t} \\
+0,05 X_{3 i t}+0,23 X_{4 i t} \\
\hat{Y}_{7 t}=-1,49+0,03 X_{1 i t}+6,31 X_{2 i t} \\
+0,05 X_{3 i t}+0,23 X_{4 i t} \\
\hat{Y}_{8 t}=-0.72+0,03 X_{1 i t}+6,31 X_{2 i t} \\
+0,05 X_{3 i t}+0,23 X_{4 i t} \\
\hat{Y}_{9 t}=6.65+0,03 X_{1 i t}+6,31 X_{2 i t} \\
+0,05 X_{3 i t}+0,23 X_{4 i t} \\
\hat{Y}_{11 t}=1,54+0,03 X_{1 i t}+6,31 X_{2 i t} \\
+0,05 X_{3 i t}+0,23 X_{4 i t} \\
\hat{Y}_{12 t}=7,29+0,03 X_{1 i t}+6,31 X_{2 i t} \\
+0,05 X_{3 i t}+0,23 X_{4 i t} \\
+0,05 X_{3 i t}+0,23 X_{4 i t}
\end{gathered}
$$


Apabila IPM di Provinsi Papua Barat dikelompokkan berdasarkan estimasi tiap intersep menjadi tiga kelompok, maka hasil pengelompokkan seperti yang disajikan pada Gambar 2 sebagai berikut:

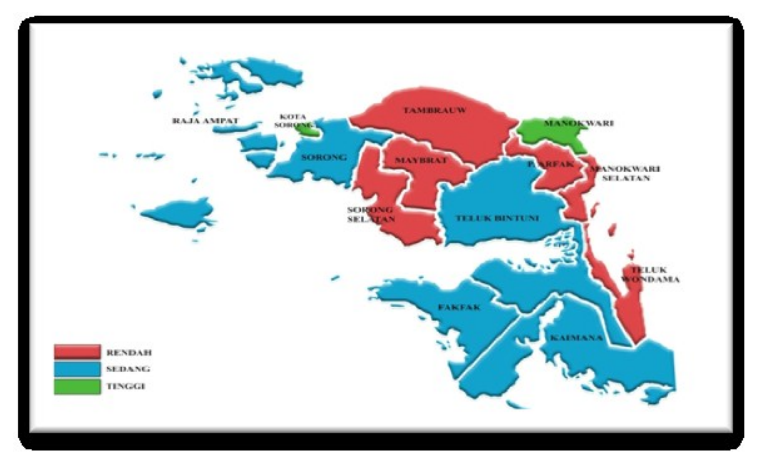

Gambar 2 Pengelompokkan IPM Tiap

Kabupaten/Kota

Pada Gambar 2 terdapat enam kabupaten/kota yang termasuk dalam kelompok IPM rendah, lima kabupaten/kota dalam kelompok sedang dan dua kabupaten/kota termasuk dalam kelompok tinggi. Artinya bahwa masih banyak kabupaten/kota yang perlu ditingkatkan kembali presentase IPM dengan menaikkan variabel-variabel bebas yang digunakan yaitu PDRB, RLS, JPM dan UHH serta faktor lainnya agar tidak terjadi kesenjangan IPM dari satu kabupaten dengan kabupaten yang lain.

\section{KESIMPULAN}

Kesimpulan yang diperoleh adalah model terbaik analisis regresi data panel yang dapat menggambarkan Indeks
Pembangunan Manusia Kabupaten/kota di Provinsi Papua Barat adalah Fixed Effect Model (FEM) dengan bentuk model sebagai berikut:

$$
\begin{gathered}
\hat{Y}_{1 t}=\hat{\alpha}_{0 i}+0,03 X_{1 i t}+6,31 X_{2 i t}+0,05 X_{3 i t} \\
+0,23 X_{4 i t}
\end{gathered}
$$

Keempat variabel bebas yang digunakan yaitu PDRB, RLS, JPM dan UHH memiliki hubungan positif terhadap IPM, dengan kebaikkan model sebesar 91\% Artinya bahwa nilai IPM di Provinsi Papua Barat dijelaskan oleh Product Domestic Regional Bruto (PDRB), Rata-rata Lama Sekolah (RLS), Jumlah Penduduk Miskin (JPM) dan Usia Harapan Hidup (UHH) sebesar $91 \%$ sisanya $0,9 \%$ dijelaskan oleh variabel lain.Variabel yang berpengaruh signifikan terhadap Indeks Pembangunan Manusia adalah Rata-rata Lama Sekolah (RLS) dan Usia Harapan Hidup (UHH).

\section{DAFTAR PUSTAKA}

Baltagi, B. H. 2005. Econometrics Analysis of Panel Data Third edition. John Wiley \& Sons Ltd., Chinester.

[BPS] Badan Pusat Statistika. 2018. Papua Barat Dalam Angka Tahun 2018. http://papuabarat.bps.go.id/ November 2019].

[BPS] Badan Pusat Statistika. 2019. Papua Barat Dalam Angka Tahun 2019. http://papuabarat.bps.go.id/ Januari 2020]. 
[BPS] Badan Pusat Statistika. 2018. Indeks Pembangunan Manusia Papua Barat 2018. http://papuabarat.bps.go.id/ [03 November 2019].

Greene, Willian H. 2002. Econometric Analysis Fifth Edition. New Jersey: Prentice Hall International.

Gujarati, Damodar N. 2004. Dasar-dasar Ekonometrika. Jakarta: Erlangga.

Hsiao, C. 2003. Analysis Of Panel Data. Cabridge University Press. Southern California.

Lestari, Andriani dan Setyawan, Yudi. 2017. Analisis Regresi Data Panel Untuk Mengetahui Faktor Yang Mempengaruhi Belanja Daerah Di Provinsi Jawa Tengah: Jurnal Statistika Idustri dan Komputasi. Vol 2, No. 1, pp. 1-11. E-ISSN 25279378.

Makridakis, Wheelwright, McGee. 1999. Metode dan Aplikasi Peramalan Jilid 1. Binarupa Aksara. Jakarta Barat.

Nachrowi, D. N. \& Usman, H. 2006. Pendekatan Populer dan Praktis Ekonometrika untuk Analisis Ekonomi dan Keuangan. Lembaga Penerbit FE UI. Jakarta.

Rizki, Muhammad., Rusgiyono, Agus., Mukid, Moch. Abdul. 2015. Pemodelan Indeks Pembangunan Manusia Di Provinsi Jawa Tengah Tahun 2008-2013 Dengan Menggunakan Regresi Data Panel. Jurnal Gaussian.Vol. 4, No. 2, Hal 345-354.

Walpole, E Ronald. 1992. Pengantar Statistika Edisi Ke-3. PT Gramedia Pustaka Utama. Jakarta.

Widarjono, Agus. 2005. Ekonometrika Teori dan Aplikasi Untuk Ekonomi dan Bisnis Edisi Kedua. Ekonosia. Yogyakarta.
Wooldridge, Jeffrey M. 2002. Econometric Analysis Cross Section And Panel Data Second Edition. The MIT Press. London, England. 